\title{
LA FILOSOFÍA CORTESANA Y EL JUEGO DE LA OCA (I). REGLAS GENERALES
}

\author{
ERNESTO LUCERO \\ Universidad de Jaén \\ ernesto.lucerosanchez@gmail.com
}

\section{INTRODUCCIÓN}

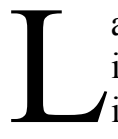

a Filosofia cortesana es una obra de naturaleza mixta, entre la palabra y la imagen, entre lo lúdico y lo didáctico. Por una parte, se publicó un manual de instrucciones que describía con precisión los movimientos de los jugadores en un juego de tabla que debía imprimirse sobre un papel suelto de buen tamaño ${ }^{1}$. Por otra, la pintura que adjuntaba el texto dibujaba una senda espiral que se encogía hacia su centro. Estaba dividida en sesenta y tres espacios numerados en los que aparecían ciertos iconos, siempre acompañados de un pareado, responsables de algunos desplazamientos de los jugadores y de otras indicaciones. Con estos mimbres, Alonso de Barros realiza la primera tematización metafórica del juego de la oca de que tenemos constancia. En ese plano, el tablero representa los medios y las dificultades que un pretensor encuentra en su trayectoria en busca del medro. La Filosofia cortesana no se agota en esa novedad. También será considerada la primera descripción española del juego, en general. Por último, su carácter político y didáctico, así como el formato de las imágenes del interior de la casilla, las acerca a los emblemas, donde el nombre de la casa es el mote o lema, la figura es la pictura y, para culminar la estructura tripartita característica, forman la suscriptio el epigrama, es decir, los versos al pie de la imagen en el tablero, y el comentario o declaración en prosa, que consta en el libro. En este terreno se trata de una de las primeras muestras del género de autor español y, lo que es aún más singular, constituye una colección de emblemas sobre un mismo asunto y al servicio de una idea común.

\footnotetext{
1 La Filosofía cortesana se publicó en Madrid en 1587. Conservamos el tablero de la tercera edición, publicada en Nápoles en 1588. El grabado es de Mario Cartaro. A todo ello nos hemos referido muy por extenso con anterioridad (Lucero, 2019a).
} 
El objetivo de Barros, muy en consonancia con la facción castellanista en que milita, radica en reivindicar el esfuerzo personal como enseña del medro conseguido. La Filosofia cortesana es un baluarte del trabajo infatigable que ha permitido a su patrón, Mateo Vázquez, cuyo nombre y cuyo escudo van en la dedicatoria, alzarse como uno de los hombres más poderosos de la monarquía hispana. En ese mismo sentido, la crítica de la ociosidad cortesana que modela el juego es una de las razones de su existencia desde una perspectiva política y moral de la cuestión (Lucero, 2019b).

Sin embargo, el discurso presenta varias contradicciones desde la misma elección del juego de la oca como referente. Por una parte, se trata de un juego de apuestas, siempre poco grato a los ojos de un moralista, y Mateo Vázquez lo era. Por otra, y esto es más grave, todo se somete al imperio de los dados, es decir, su dinámica excluye en última instancia la acción personal del logro de cualquier objetivo. El significado traslaticio aparece con frecuencia en otros juegos donde la oposición de los jugadores genera una concepción agonística vinculada a la guerra, una guerra atenuada y sublimada por el proceso de la civilización. Veremos que Barros intenta sostener esta característica sobre la base de la pugna de los pretensores por la merced, inaugurando así el ciclo muy prolífico de las ocas temáticas ${ }^{2}$. Étienvre (1990: 288) piensa — seguramente, con razón—que solo los naipes mezclan agon y alea con pleno acierto, pero Barros demuestra que en su adaptación del juego de la oca puede crearse esta ficción de entorno competitivo basado en el azar, una ficción capaz de sostener una metáfora política, donde la estrategia brilla por su ausencia, pero se recupera sobre la base de una falacia que explicaremos con brevedad al final de estas páginas.

Este estudio analiza, pues, el proceso de adaptación del juego de la oca a la Filosofía cortesana como divertimento moral. Para ello, en primer lugar, revisaremos las reglas del juego de procedencia, de moda por aquellos años en las cortes europeas. Después, observaremos la selección de Barros, su grado de aceptación de las pautas que admite y el ajuste final por analogía al universo áulico. Nos ceñiremos aquí a las reglas generales, dejando la investigación de las casas marcadas y sus consecuencias para otra ocasión.

\section{El JUEGO de LA OCA. La FiLOSOFí CORTESANA COMO PRIMERA OCA TEMÁticA}

No todos los juegos son iguales. En la época de la Filosofía cortesana triunfaban los dados y, sobre todo, los naipes que, sin embargo, se consideraban nocivos para el individuo y para la sociedad. De ahí que recibieran sanciones reprobatorias de

2 Sobre ocas temáticas, véase Martínez Vázquez de Parga (2008: 291-307). También existieron barajas temáticas desde principios del siglo XVI, que no son de este lugar (Infantes, 2014: 20-22). 
carácter moral. Además, se promulgaron prohibiciones legales que, no obstante, nunca llegaron a impedir su ejercicio y disfrute ${ }^{3}$. Barros necesitaba crear un juego que produjese lícito deleite y honesto aprovechamiento para reivindicar una forma de vida cortesana más que virtuosa, en realidad, discreta, pero que no ocasionase problemas. El punto de partida de su tablero será por eso el juego de la oca.

Dejando de lado los orígenes míticos o históricos del juego, que no son de este lugar, así como su hermenéutica simbólica o esotérica ${ }^{4}$, el juego de la oca se define como de puro azar, de alea, en la clasificación de Roger Caillois. Barros, por si no bastase, lo concibe como un juego de apuestas. Con esas características resulta sorprendente no hallar una condena explícita de moralistas de toda ralea ${ }^{5}$ que siempre ven con recelo las pasiones que desatan en los jugadores esas apuestas o

3 No podemos detenernos en estas cuestiones anejas, bien conocidas, por otra parte. Valga una referencia a González Alcantud (2003: 71 y ss.) y a Infantes (2014: 50-51).

4 Sin ánimo de exhaustividad, podemos decir que la génesis mítica del juego de la oca se remonta a Palamedes, creador también de los dados, del ajedrez, de la balanza o del alfabeto griego, entre otras invenciones de la misma magnitud, durante el sitio de Troya. Se ha cuestionado como antecedente remoto el llamado disco de Phaistos o Festos $-\mathrm{y}$ más recientemente también el desaparecido disco de Vladikaukaz — , que para Martínez Vázquez de Parga constituye el primer juego de la oca, si bien, en opinión de Gómez-Morán, es un calendario, como también lo es el propio juego, a partir de su diseño sobre el número 13. Este último trabajo atribuye a Barros la opinión de que el juego procede de alguna secta herética protestante, pero nuestro aposentador nunca se pronunció en tal sentido (Gómez-Morán, 2005: 36 y 40). Parece más plausible que la identidad entre disco y juego la interpretación arqueo-astronómica de Francisca Martín-Cano. Otros, entre los que se cuenta Sagrario López Poza, consideran más un origen remoto oriental, ceñido al juego chino «inventado bajo la dinastía Ming (1368-1644) llamado Shing Kunt t’o, que puede traducirse como la promoción de los mandarines» (López Poza, 2004: 67). No faltan otras interpretaciones simbólicas: el juego de la oca sería un plano espiritual del Camino de Santiago, vinculado a la Orden del Temple (Alarcón, 2001; Lalanda, 2013), o mapa de la ruta de los metales (Gómez-Morán, 2005). Sus antecedentes más próximos hay que rastrearlos en aucas o aleluyas (Amades, 1950; Alarcón, 2001; Infantes, 2010, 2014 y 2015) y en laberintos (Rodríguez de la Flor, 2007; Infantes, 2014), en algunos juegos infantiles o de carácter adivinatorio, como el Libro de las suertes (Ruiz Pérez, 2009: 37, nota 7); puede que el juego mántico se transformara en un juego infantil semejante a la rayuela, que predecía el futuro por alectriomancia, y que este diera origen al juego de mesa (Amades, 1950; Lorenzo Vélez, 1981). Puede, finalmente, que la celebración de la Martinalia (Mascheroni y Tinti, 1981) supusiera el sacrificio que diera nombre al juego (D'Alemagne, apud Mascheroni y Tinti, 1981: 13).

5 José Antonio González Alcantud remite a una eventual prohibición del juego en la Novísima recopilación de la que no he hallado rastro en Izu Belloso (1994: 72). Están vedados, eso sí, los juegos adivinatorios como el Libro de las suertes, aunque se presentaba como remedio de la terrible ociosidad. Por eso señala Rosa Navarro que si la Iglesia hubiera percibido el carácter mántico de la oca, la habría prohibido con base en la disposición IX de Trento (Navarro, 2005: 64); véase Amades (1950). También todos aquellos que combinan apuestas y azar (dados, naipes), pero no otros que introducen estrategia, señaladamente, el ajedrez. Sobre el pensamiento moral medieval alrededor del juego, véase Molina (1997-1998). 
la ignorancia de lo porvenir que subyace al azar, contrario, además, a la doctrina religiosa católica que impera en los reguladores (González Alcantud, 1993: 78).

En todo caso, no parece que la oca levante rencores enconados y eso a pesar de que su prohibición no habría afectado de modo significativo a las arcas de la Corona, a diferencia de lo que toca a la proscripción de las cartas (Deleito, 2008: 228). Tampoco es probable que diese lugar a grandes movimientos pecuniarios o a sonadas bancarrotas. Al no tropezar con demasiadas trabas, el juego de la oca se ha implantado con tranquilidad en las cortes europeas desde un núcleo de irradiación italiano que se manifiesta en los primeros tableros conservados, lo mismo que en algún testimonio como el muy conocido de Pietro Carrera, que reseña la entrada de esta distracción en la corte gracias a un regalo de Francesco de Medici al monarca, y que cita la existencia de la variante de Barros. El propio rey comenta en sus cartas personales la afición que sienten algunos miembros de la familia y que se puede contrastar con la simpática epístola del bufón Gonzalillo a un noble italiano, que recuperó Nieves Baranda ${ }^{7}$. Además del agrado con que la Corona recibió el juego, milita en favor de su moralidad su antigua asociación con el ajedrez en el primer tablero conservado, que data de la primera mitad del siglo XVI, una tabla reversible de madera tintada que obra en el Museo Metropolitano de Nueva York ${ }^{8}$.

6 Esos impulsos y emociones que deben de común ser contenidos en un ámbito reglado como la corte, en los momentos de esparcimiento, estallan, al punto de que los jugadores echan mucha más sal de la precisa para sazonar, que era la autorizada recomendación de santo Tomás sobre el caso (Molina, 1997-1998: 218). Precisamente, se juega para eso: «muchas actividades recreativas nos proporcionan un escenario ficticio para hacernos sentir una excitación que imita de algún modo la producida por situaciones de la vida real aunque sin los peligros y riesgos que esta conlleva» (Elias y Dunning, 1992: 57). Pero todo exceso de emoción resulta impredecible. De ahí que se persigan los naipes o los dados con prohibiciones que, sin embargo, se incumplirán de manera sistemática (véase González Alcantud, 1993: 85 y 90).

7 El rastro reciente más antiguo aparece en un «oscuro libro de sermones» fechado en 1480 (Sevi1le, 2016: 116-117). Hay otras menciones notables que menudean en los libros de los especialistas, como la muy sonada del tercer libro de Pantagruel de Rabelais, que Seville entiende que se puede interpretar en buena medida como un irónico juego de la oca; o la presencia de una posible oca en el óleo El triunfo de la muerte (c. 1568), de Pieter Brueghel, el Viejo, al que dedica unas líneas Martínez Vázquez de Parga (2008: 277). Sobre los testimonios mencionados, véanse Carrera (1617: 25), Baranda (2010: 50-58), Infantes (2010 y 2014) y Bouza (1988: 125). Donatino Domini advierte de que las palabras de Carrera no están verificadas, aunque resultan verosímiles (Domini, 1985: 85).

8 Remito para el estudio de este y de los tableros que se se mencionan a continuación a la completísima colección Giochi dell'Oca e di percorso, de Luigi Ciompi y Adrian Seville <http:// www.giochidelloca.it>, de muy sencilla consulta, y señalo el número que ocupan en ella. Este tablero, por ejemplo, es el archivo n. ${ }^{\circ}$ 1.673. Los siguientes, por su orden de aparición, llevan los números 2.260, 2.317, 252, 1.104 y 1.108 , respectivamente. El tablero que corresponde a la edición napolitana de la obra de Barros es el número 1.103. 
Ha pervivido también un elemental juego titulado «Giuoco dell Oca» diseñado a mano y que se supone de la segunda mitad del siglo XVI. Si por una parte resulta mucho más barato imprimir un suelto que una baraja, por ejemplo, este papel plantea una difusión todavía más amplia, ya que no es preciso acudir a las planchas y es más que probable que se dibujasen incluso en la tierra improvisados recorridos con los que emprender una partida, en una vuelta al origen, si es que ese fue, como sostienen algunos. De la década de la obra de Barros nos han llegado varios ejemplares más. Il Diletevole Gioco del Ocha, papel sobre lienzo que pertenece al Museo Británico 9 o Il Novo Gioco de Loca, xilografía anónima con una pareja en el centro de la espiral que anticipa resoluciones del Jardín de amor o del Juego de Cupido. Estas son todas las ocas existentes anteriores a nuestro tablero de los que tenemos noticia. Ninguna de ellas supone una transmutación del campo corriente del juego con respecto a otro ámbito semántico o de pensamiento, ninguna transformación metafórica. De ahí que podamos afirmar que la originalidad de Barros se sustenta, en primer término, en haber observado las posibilidades de esa susceptibilidad metafórica, tan fértil desde entonces.

Parece, por los tableros conservados, que en esos años se vive una moda cortesana que Alonso de Barros supo adaptar y a la que se sumó si atendemos a las declaraciones que hablan de su difusión por Italia y en Indias. Barros, no obstante, tiene un conocimiento del juego de la oca muy superficial, en algunos aspectos, e interesado, en otros. Seguramente disfrutó de él durante su servicio en Italia o quizá más tarde, en la corte madrileña, cuando su popularidad estaba en la cresta de la ola. Pero es un hecho que no conoce bien la totalidad de las reglas ni responde a los significados mágicos que pulsan en las casas marcadas o al simbolismo de la locación numérica de ciertos elementos. En cambio, tiene clara la concepción del itinerario como representación de la vida y atisbará con acierto sus muchas posibilidades a partir de esta analogía básica, así como el valor iniciático del juego, en un sentido más pedestre de lo común, si se quiere, pues no persigue una renovación espiritual ordenada al bien, sino una reflexión de carácter pragmático que, de ofrecer una dimensión moral, consistirá en un aprendizaje dirigido

$9 \quad$ Este juego y otros más parecen aludir de un modo u otro a que el premio obtenido por el ganador es el animal que le da nombre, de donde procedería según algunos la propia denominación de polla para la apuesta, acepción que todavía pervive en muchos países de Hispanoamérica. También en Il Piacevole Gioco Dell'Ocha se puede observar un pequeño banquete en el centro, como se aprecia en la maravillosa estampa de Carlo Coriolani Il Dilettevole Gioco di Loca, grabada en Venecia hacia 1640, que deja ver a través de la ventana de fondo una escena de caza. Algunos comentarios sobre este asunto se pueden leer en Mascheroni y Tinti (1981: 10-13); la tavola III, anónima, del siglo XVII (Mascheroni y Tinti, 1981: 11), presenta más allá de la consabida reunión alrededor de la mesa del hueco central, algunos juegos con ocas, más o menos civilizados, pero muy llamativos (la cucaña, o el goose pulling que, entre nosotros, ha sobrevivido en Lekeitio hasta que recientemente se comenzó a sustituir los animales por gansos de goma). 
a la eficacia de los propios actos, pues al recorrer el tablero de 1588 se desvelará al peregrino una serie de conocimientos útiles para la vida en la corte que pueden generar una variación del estado y posición social del cortesano. Se trata, pues, de asimilar ideas curiales básicas, como los caminos del medro, el doble filo de la discreción o la asunción del desengaño.

Después de esta aproximación a la naturaleza esencial del juego de la oca y a su entrada en las cortes europeas en el siglo XVI, conviene recordar en este punto sus reglas básicas para poder extraer conclusiones sobre la remodelación que acomete Barros. A eso dedicamos las próximas líneas.

El tablero consta de 63 casillas dispuestas en una espiral interior por las que se moverán las fichas de los jugadores en función de la puntuación que obtengan con los dados. Ganará el primero que llegue a la última con el tanteo exacto de puntos, pues si obtiene alguno de más, se producirá un rebote. Dos jugadores no pueden ocupar el mismo emplazamiento, por lo que si uno de ellos cae en una casilla en que se encuentra otro lo reemplazará, mientras que el primero volverá a la casilla de origen del segundo.

A lo largo del camino existen varias casillas especiales, que establecen reglas concretas de debido cumplimiento. Algunas son afortunadas, pero otras suponen un obstáculo para la consecución del objetivo. La figura más destacada es la oca, que da nombre al juego, pues quien llega a esta casilla no se detiene, sino que avanza desde ahí los tantos que le guiaron a ella. La oca aparece en múltiples lugares, pero no se encuentra distribuida su presencia de manera azarosa. Surge en dos series que discurren entrelazándose cada nueve espacios a partir de la oca del número $5 \mathrm{y}$ de la del número 9 . Por tanto, serán representaciones de este animal las casillas 5, 14, 23, 32, 41, 50 y 59; 9, 18, 27, 36, 45, 54 y 63 (sea o no el Jardín de la oca).

Otra casa de muy buena ventura es la de los Dados. Si un jugador en su primera tirada obtiene una puntuación de 9 , de inmediato se desplazará a una de las casas ilustradas con dos dados, que muestran en sus caras vistas combinaciones que suman esa cantidad. Si el número lo ha obtenido por la suma de $6+3$, se ubicará en la casilla 26 , donde un dado marca 6 y otro 3 ; y si fue como resultado de lograr $4+5$, podrá trasladarse a la casilla 53 , con lo que cobra una gran ventaja sobre sus oponentes. Es notorio que la regla de la tirada inicial se ha creado para evitar que un jugador que obtenga un 9 al comenzar la partida la gane de inmediato como consecuencia de la regla de la casilla de la oca, que acabamos de comentar ${ }^{10}$. Además, existe una correspondencia entre las dos casillas que supone el movimiento

10 Es muy explícito a este respecto el «Juego real de Cupido» (c. 1620), de base 7, cuyas reglas dicen literalmente: «Y por cuanto los Cupidos son puestos de 7 en 7 y que haciendo el número 7 del primer golpe de dados se ganará el juego sin dificultad, lo cual no es razón, se debe tomar consideración de qué maneras será compuesto el dicho número de 7 , porque si es de 6 y 1 , se 
del jugador que, en el transcurso de la partida, cae en cualquiera de ellas, movimiento que se producirá en ambas direcciones, de dados a dados.

Conste que en el juego, con independencia de los valores que estemos dispuestos a conceder en el plano simbólico a cada cifra, se cuenta indudablemente con una base numérica de la que no podemos abstraernos si queremos entenderlo y si queremos comprender las interpretaciones que se le han venido dando a lo largo de la historia. No cabe duda de que el juego de la oca se asienta sobre el número 9. Que lo consideremos un símbolo de la totalidad o simplemente el número 9 es otra cosa, pero quien distribuyó la espiral en 63 casas lo tuvo presente y le atribuía algún significado adicional, de la misma manera que las ocas han sido consideradas tradicionalmente un animal protector ${ }^{11}$. Por ese camino hay quien ha destacado una progresión descendente en los intervalos entre casillas marcadas, como Martínez Vázquez de Parga, o quien se ha aplicado a la gematría con mejores o peores resultados ${ }^{12}$.

No es habitual en los juegos recreativos que exista una casilla que suponga que el jugador lo pierda todo, en particular en caso de divertimentos infantiles, como es ahora la oca - aunque no lo fue siempre, ni menos en el supuesto que nos incumbe, el de la Filosofía cortesana - En realidad, se trata de una necesidad inexcusable para resolver lo que hoy, con un anglicismo quizá innecesario, se conoce como un bug $^{13}$, un error no intencionado del diseño del tablero sobre los pilares del número 9 que ofrece resultados anómalos. Nos estamos refiriendo a la Muerte. Aunque la exégesis que se ha dado tanto al elemento que nos encontramos como a su inveterada, recurrente e inexcusable presencia en el número 58

debe poner en el círculo marcado 16 ; si es de 5 y 2 , en el círculo de 25 ; y si es de 4 y 3 , en el círculo de 43 . Y después continuar de jugar por su hilera».

11 Repárese en que la forma gráfica del propio número 9 recrea una especie de espiral.

12 «Salida $+5=6$, elPuente; $6+13=19$, la Posada $6+13+12=31$, el Pozo $; 6+13+12+11=42$, el Laberinto; $6+13+12+11+10=52$, la Cárcel; $6+13+12+11+10+6=58$, la Muerte; $6+13+12+11+10+6+5=63$, el Jardín» (Martínez Vázquez de Parga, 2008: 197). Los obstáculos están separados por un número de casillas decrecientes $13,12,11,10$, progresión que se rompe en el 58, como admite Adrian Seville, aunque la autora intente arreglarlo con esa simetría del cinco. Rafael Alarcón, por su parte, ha aplicado las reducciones cabalísticas para atribuir significados a algunas posiciones y asegura, además, que las casas especiales señalan trece etapas, como recomienda el Codex Calixtinus para recorrer el Camino de Santiago, con el que asocia el juego (Alarcón, 2001: 90-94). Martín Cebrián encuentra que los números donde se asientan las ocas suman cinco o nueve, excepto el 59, de lo que pretende extraer algún significado causal escondido, 5+9=14, el número total de ocas (Martín Cebrián, 2005: 74). No parece que nadie haya reparado en que los dados ocupan casillas en las que la suma de sus dígitos da $8(5+3$ y $2+6)$, lo cual no puede ser casual para quien se enmarque en una línea de pensamiento cabalístico, mas renunciamos a extendernos.

13 ABC, reseña a Kanat-Alexander. Otros sitúan dicha casilla dentro de la ruta jacobea a Santiago de Compostela, lugar que para muchos supone el final del camino, aunque en verdad se encuentra más allá, en la costa (Alarcón, 2001: 88-89). 
(recuérdese que $5+8=13$, número maldito, que corresponde a la muerte en el tarot) ha sido densa y prolífica, la explicación es más sencilla: un jugador que obtuviese un nueve al lanzar los dados desde ese espacio, la casa 58, por la combinación de dos reglas que ya conocemos, acabaría en la casilla número cinco, ya que el rebote en la casilla final lo conduciría a la oca que se halla en el 59, y echando nueve puntos hacia atrás, es decir, tantos como le han conducido a dicha casa, recorrería el camino en sentido inverso de oca en oca. Quien diseñara el tablero se apercibió de este problema e ideó una casilla especial donde el jugador no pudiera detenerse y la asoció a los avatares de la fortuna o con el simbolismo del eterno retorno en el ciclo natural (Seville, 2016) ${ }^{14}$.

Barros soluciona este problema de una vez, y sin habérselo siquiera planteado, cuando desplaza la Muerte del Valedor a la casa 46, eliminando por completo de esa manera el significado numérico asociado a las posiciones de las ocas o a las divisiones del recorrido. No es lo mismo, por cierto, la Muerte que la Muerte del Valedor, pero a efectos del logro de una pretensión, el fallecimiento de quien puede proporcionar la merced equivale a la necesidad de volver a punto de salida. Nótese que el sentido de la muerte es aquí literal, no simbólico.

Tampoco respetará la ubicación de los demás elementos tradicionales: los Dados no conservan su posición estándar (se hallan en las casas 28 y 53) y no se representan con el valor supuesto que remite a la regla de la tirada inicial, también de base 9 . De hecho, se trata de tres cubos y no de dos, cuyas caras vistas suman 6 y 11. A su vez, el elemento principal del tablero, la oca, se cambia por una yugada de bueyes, que simbolizan el Trabajo. La sustitución del animal benéfico implica la renuncia a su simbolismo trascendente, pero habrá que transferir su relevancia al emblema que la suple, el Trabajo. Por lo demás, en lugar de disponer su ubicación de manera exhaustiva, se desentiende abiertamente y muestra una total indiferencia:

En el número de las casas del Trabajo no se guarda orden, porque no la tiene la materia de que aquí se trata, no obstante que hay sin la primera otras ocho casas, que todas ellas con sus letras animan al pretensor para que no le tema, y le enseñan a que le busque y procure por lo mucho que importa y bienes que dél resultan [...] (Barros, 2019: 146).

Su colocación precisa en el tablero italiano de la tercera edición de la obra -el único que conservamos- ocupa las casas $4,12,17,23,30,34,41,48$ y 57, sin que se observe secuenciación alguna, por más que sean nueve, y sin que Barros la pretenda. Podría haberse situado el Trabajo en lugares diferentes — aunque

14 Matizamos en este trabajo que, en realidad, son tres casas las debidas a la base numérica del juego: la Muerte — como indica Seville—y también los Dados. 
próximos-, dentro de unos márgenes que mantuvieran cierta armonía en su reparto por el tablero.

Otra cosa es el número 63. Barros mantiene la configuración original, que hace el tablero reconocible, familiar al juego cuya esencia está transformando. El número 63 guarda relación con las edades del hombre, como las siete ocas de cada serie, que señalan puntos de inflexión que introducen cada una de las siete etapas de la vida. Las casas del recorrido son para Barros «los años de la vida que se gastan en una pretensión y los que también la gastan a ella», hasta el climaterio ${ }^{15}$.

Alonso de Barros también toma el grueso de las restantes reglas básicas del juego primigenio: el rebote, la imposibilidad de que dos jugadores se hallen en la misma casilla de manera simultánea y las consecuencias de este suceso, la adopción de casas mecánicas como la oca o los dados, con las precisiones que hemos explicado y, finalmente, la división del tablero en casas marcadas y no marcadas, aunque con ajustes notables para dar cabida a su enseñanza cortesana al percibir las posibilidades didácticas de la retórica silenciosa de la imagen en la transmisión de valores en cada casa especial. Las casas marcadas son capaces de provocar desplazamientos de los jugadores en el tablero y de promover otras condiciones - pagar un tanto al centro o a otro jugador, por ejemplo-, como en el juego de la oca original. Su ubicación carece de un orden cabalístico, pero se sostienen algunas posiciones relativas que permiten hacer explícito un golpe de Fortuna a favor o en contra del pretensor, que se mueve en el tablero, como lo haría en la corte. Pongamos por caso que quien padece la Mudanza de Ministros debe comenzar el proceso de la Adulación de otro valedor que lo sustituya, lo que producirá el desalojo de la primera casa, que lleva el número 43, en dirección a la segunda, situada en el número 10. Lo contrario carecería de sentido en la carrera del cortesano que ilumina el juego de Barros ${ }^{16}$.

En conclusión, Alonso de Barros adaptó de manera libérrima el juego de la oca, manteniendo algunos elementos de referencia para que resultase reconocible pero vaciando de significado profundo la numeración y la posición de las casas más notables. Al desprenderlo de cualquier connotación mágica, mántica

15 Véanse «Declaración del juego y orden de jugarle» (Barros, 2019: 169); y Mexía (2003: 283 y ss.). Por supuesto, aunque Barros conoce muy bien el libro, no va más allá de lo expuesto. Mexía, en cambio, dice que los años aciagos se llaman «climiterios». El paso de cada uno de los setenarios o etapas de la vida producían temor y «el más temido de todos era el año sesenta y tres [...] Por lo cual, cuando un hombre llegaba a esta edad, él tenía grande cuidado y vigilancia en su vida y todos estaban esperando qué sería dél» (Mexía, 2003: 292-293). Las advertencias en este sentido tocan también a nuestro Felipe II (véase Campos, 2009: 25). Pueden verse los preciosos grabados de las edades del hombre o de la mujer de Christophano Bertelli, de mediados de siglo.

16 Barros concede un lugar de relieve a la casa de Fortuna, como muestra de su importancia en la concepción del juego. Se halla en el número 51 para posibilitar que la tirada extra que permite al jugador pueda conducirlo a ganar la partida si obtiene dos seises, favorecido por la diosa. 
o esotérica - por puro desconocimiento, a buen seguro-, puede presentarlo como un divertimento honesto para entretener el ocio cortesano. Las apuestas del juego no suponen óbice. Pueden poner el punto de sal que toleraba santo Tomás pero, una vez incorporada en su evolución la regla de la tirada inicial, la oca no puede ocasionar graves consecuencias pecuniarias por la propia naturaleza de su lento desarrollo. Más aún en el caso de la Filosofía cortesana, donde es imposible ganar la partida desde la Puerta de la Opinión (la casilla de salida) puesto que las casas del Trabajo no son equidistantes entre sí. No lo son en el tablero de 1588 y no lo podrían ser, en ningún caso, si no se modifica la ubicación de la casa de Qué Dirán, que ocupa el número 36, uno de la serie de las ocas de múltiplos de 9.

Tan solo se le podría achacar que todo jugador quede a expensas del azar. Tal y como hemos explicado en otro lugar, parece contradictorio que Alonso de Barros, en una obra donde ensalza el trabajo constante para obtener las mercedes anheladas o un mejor estado, subordine el destino final de los contendientes a la tirada de dados y reconozca a la Fortuna su preeminencia sobre la yunta de bueyes en que cifra el esfuerzo humano ${ }^{17}$. El juego es una ficción, pero la vida en la corte es también un juego donde las circunstancias determinan en muchas ocasiones el destino del individuo. En definitiva, no es tanto que la forma no se corresponda con el contenido - el empleo de un juego de azar para exaltar el trabajo - como que Barros, quizá sin pretenderlo, represente la vida en la corte de un modo más realista y fidedigno de lo que a priori le dictaba su ideología castellanista.

Alonso de Barros enseña deleitando, contamina el juego de la oca con la emblemática, de raíces políticas y cortesanas bien conocidas, género que también concibe la imagen como propedéutica, al tiempo que esa misma imagen motiva un juego interpretativo (Blas et alii, 2011: 49), que se suma a los valores lúdicos preexistentes en la oca. Un juego serio. Una enseñanza recreativa. Una crítica de la ociosidad del ocio en la corte. Una reivindicación un tanto ingenua de la capacidad del Trabajo para imponerse a Fortuna y un aprendizaje en la asunción senequista de sus reveses hacia la construcción personal y el conocimiento de uno mismo.

17 Hemos desarrollado en profundidad estas ideas en otros lugares (Lucero, 2019b). 


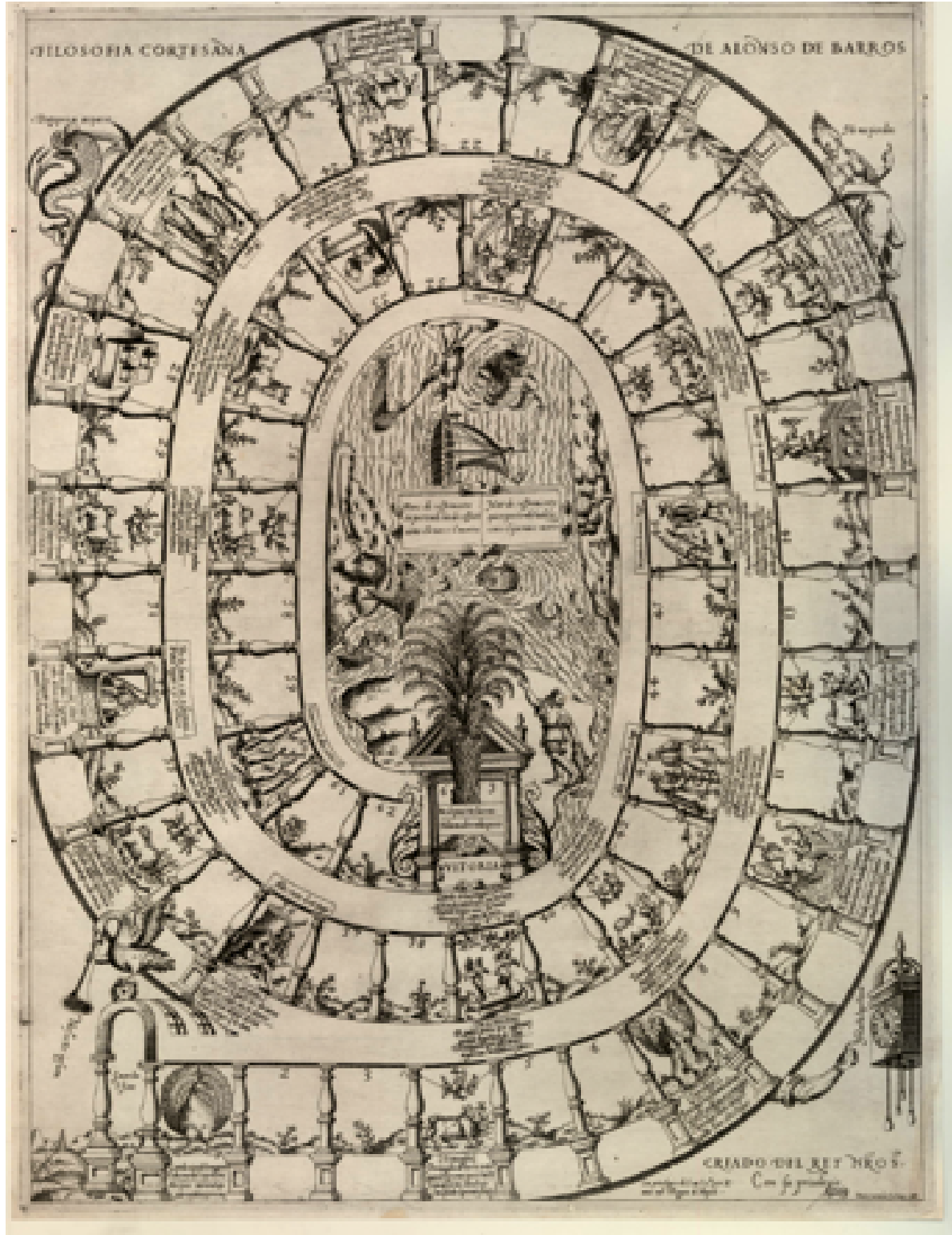

[Imagen 1]. Filosofia cortesana de Alonso de Barros. Mario Cartaro. Nápoles, 1588. (C) The Trustees of the British Museum: AN137041. 
BIBLIOGRAFÍA

Alarcón, Rafael (2001). A la sombra de los templarios. Los enigmas de la España mágica. Barcelona: Ediciones Martínez Roca.

Amades, Joan (1950). «El juego de la oca». Bibliofilia, 3, pp. 1-21.

BARANDA, Nieves (2010). «Las epístolas bufonescas de Gonzalo de Liaño a la Gran Duquesa de Toscana». Pierre Civil y Françoise Cremaux (eds.), Actas del XVI Congreso de la Asociación Internacional de Hispanistas. Nuevos caminos del hispanismo. Madrid / Frankfurt am Main: Iberoamericana / Vervuert, pp. 50-58.

Barros, Alonso de (2019). Filosofía cortesana. Ernesto Lucero (ed.). Madrid: Polifemo.

Bernat Vistarini, Antonio y John Cull (1999). Enciclopedia de emblemas españoles ilustrados. Madrid: Akal.

Blas, Javier, María Cruz de CARlos y José Manuel Matilla (2011). Grabadores extranjeros en la corte española del barroco. Madrid: Biblioteca Nacional de España / Centro de Estudios Europa Hispánica.

Bouza Álvarez, Fernando (1988). Cartas de Felipe II a sus hijas. Madrid: Turner.

CAILlois, Roger (1986). Los juegos y los hombres, la máscara y el vértigo. Ciudad de México: Fondo de Cultura Económica.

CAmpos, Francisco (2009). «Felipe II íntimo. El rey y el trabajo personal vistos a través de su correspondencia». Cuadernos de Investigación Histórica, 26, pp. 21-58.

Carrera, Pietro (1617). Il giocho degli scacchi. Militello: Giovanni de Rossi da Trento.

Ciompr, Luigi y Adrian Seville (2014). «Giochi dell’Oca e di percorso», catálogo en línea $<$ http://www.giochidelloca.it> [Consulta: 08/01/2018].

Deleito Piñuela, José (2008). La mala vida en la España de Felipe IV. Madrid: Alianza Editorial.

DomINI, Donatino (1985). Giochi a stampa in Europa dal XVII al XIX secolo. Ravenna: Longo Editore.

Elias, Norbert y Eric DunNing (1992). Deporte y ocio en el proceso de la civilización. Ciudad de México: Fondo de Cultura Económica.

ÉtIEnVRe, Jean-Pierre (1990). Márgenes literarios del juego. Una poética del naipe. Siglos XVI-XVIII. London: Tamesis Books.

GómEz-Morán, Ángel (2005). «El juego del laberinto y su tótem ánade». En Juego de la oca. Catálogo de la exposición. Valladolid: Fundación Joaquín Díaz.

GonZÁlez Alcantud, José Antonio (1993). Tractatus ludorum. Una antropológica del juego. Barcelona: Anthropos.

INFANTES, Víctor (2010). «Una pintura que se contiene en un pliego grande. El tablero de la Filosofía cortesana de Alonso de Barros: una Oca emblemática entre España e Italia (1587 y 1588)». Imago. Revista de Emblemática y Cultura Visual, 2, pp. 127-135.

INFANTES, Víctor (2014). Ludo ergo sum. La literatura gráfica del juego áureo. Madrid: Turpin editores.

INFANTES, Víctor (2015). Lyra mixta. Silva ejemplar de artificios gráfico-literarios. Madrid: Turpin editores.

Izu Belloso, Miguel José (1994). «Los juegos de azar en el Derecho histórico y en el Derecho actual de Navarra». Revista Jurídica de Navarra, 17, pp. 69-80. 
Lalanda, Fernando (2013). El juego templario de la oca en el Camino de Santiago. Madrid: Visión libros.

LóPez PozA, Sagrario (2004). «Expresiones alegóricas del hombre como peregrino en la tierra». En De oca a oca... por el Camino de Santiago. Santiago de Compostela: Xunta de Galicia, pp. 49-72.

LoRENZO VÉLEZ, Antonio (1981). «Algunos juegos infantiles en su aspecto mántico». Revista de Folklore, 7, pp. 11-15.

LuCERo, Ernesto (2019a). «El tablero de juego de 1588 en las ediciones madrileñas de la Filosofia cortesana de Alonso de Barros». Romance Notes, 59.1, pp. 197-206.

LuCERo, Ernesto (2019b). «La idea del trabajo en la Filosofia cortesana de Alonso de Barros». Hipogrifo. Revista de Literatura y Cultura del Siglo de Oro, 7.2, pp. 821-834.

Martín-CANO, Francisca (2002-2005). «Significado arqueoastronómico del Disco de Phaistos». En Soliman Orta (ed.), Portal Tartessos <http://www.tartessos.info/html/ arqueo_festos01.htm> [Consulta: 08/01/2018].

Martín Cebrián, Modesto (2005). «De oca en oca: un viaje por el azar». En Juego de la oca. Catálogo de la exposición. Valladolid: Fundación Joaquín Díaz, pp. 69-86.

Martínez VÁzquez de Parga, María José (2008). El tablero de la oca. Juego, figuración, símbolo. Madrid: 451 Editores.

Mascheroni, Silvia y Bianca Tinti (1981). Il gioco dell'Oca. Un libro da leggere, da guardare, da giocare. Milano: Bompiani.

Mexía, Pedro (2003). Silva de varia lección. Isaías Lerner (ed.). Madrid: Castalia.

Molina Molina, Ángel-Luis (1997-1998). «Los juegos de mesa en la Edad Media». Miscelánea Medieval Murciana, 21-22, pp. 215-238. DOI: https://doi.org/10.6018/j7861.

Navarro Durán, Rosa (2005). «Los libros del juego de las Suertes». En Juego de la oca. Catálogo de la exposición. Valladolid: Fundación Joaquín Díaz, pp. 57-68.

Rodríguez de la Flor, Fernando (2007). Era melancólica. Figuras del imaginario barroco. Barcelona: José J. de Olañeta ediciones / Edicions Universitat de les Illes Balears.

Ruiz Pérez, Pedro (2009). «Días lúdicos: juego, ocio y literatura». En Enrique García Santo-Tomás (ed.), Materia crítica: formas de ocio y de consumo en la cultura áurea. Madrid / Frankfurt am Main: Universidad de Navarra / Iberoamericana / Vervuert, pp. 35-58.

SEville, Adrian (2016). «The Medieval Game of the Goose: philosophy, numerology and symbolism». En Eddie Duggan y David W. J. Gill (eds.), From cardboard to keyboard. Proceedings of Board Games Studies Colloquium XVII. Lisbon: Associação Ludus, pp. 115-135.

SIN FIRMA (2015). «¿Qué es un bug?». $A B C, 26$ de febrero de $2015<$ http://www.abc.es/ tecnologia/consultorio/20150226/abci--201502252129.html> [Consulta: 07/01/2018].

Recibido: $12 / 06 / 2019$

Aceptado: 25/01/2020 


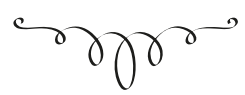

\section{LA Filosofía CORTESANA Y EL JUEGO DE LA OCA (I). Reglas GENERALES}

Resumen: La Filosofía cortesana contiene las indicaciones necesarias para desarrollar una novedosa adaptación del juego de la oca a la realidad de la corte. Alonso de Barros afronta con entera libertad las reglas originales del juego de tabla para someterlas a su intención de representar las estrategias del medro desde su ideología castellanista. Para ello mantiene la configuración esencial del tablero, que lo hace reconocible, pero desconoce, ajusta o modifica buena parte de las bases del juego.

Palabras clave: Alonso de Barros, Filosofía cortesana, juego de la oca, literatura cortesana, ocio, corte, emblemática.

Filosofía cortesana and Game of the Goose (I). General rules.

Abstract: Alonso de Barros' Filosofia cortesana (Court Philosophy) accounts for the right instructions to develop a new adaptation of the Game of Goose to the Court reality contains the necessary indications to develop a novel adaptation of «The Game of the Goose» to the courtly reality of the Court. Alonso de Barros faces freely the original instructions of the board game, so that he can apply them to his intention of representing the strategies to improve their social position from his Castilian ideology. In order to do so, he adheres to the essential shape of the board game, which makes it recognizable, but he ignores, amends or modifies a considerable part of the game basics.

Key words: Alonso de Barros, Filosofia cortesana, Game of Goose, Court Literature, Leisure, Court, Emblem. 